\title{
Values education: a new direction for medical education
}

\author{
Rivka Grundstein-Amado ferusalem, Israel
}

\begin{abstract}
This paper suggests that medical education should redirect resources to values education, specifically developing new strategies to improve the process of clarification of values. The author suggests using the values journal method which is based on a systematic record of students' personal value systems reflected in their stories and life experience; and on their responses to case presentation. Generating a personal values journal helps students define who they are, what their social and professional roles are, what their expectations are and where they are going. Keeping values journals promotes students' decision-making capacity, and equips them with the necessary skills to teach their future patients how to generate their own value systems. The development of a well defined values journal is a preparatory stage for active participation in clinical conferences or group discussion, and for effective communal dialogue among the group's members.
\end{abstract}

\section{Introduction}

Over the past 25 years, medical ethics education has become an integral part of the core curriculum in most of the American medical schools (1). The medical ethics programme is a broad curricular effort that aims to enhance physicians' understanding of their own values, and to improve their decisionmaking processes when they face value-conflict situations which arise during clinical practice (2). The domain of values pervades every aspect of the clinical encounter. Each individual decision-maker (for example, physician, patient, family member and other health-care providers) carries a subjective set of beliefs and values and a distinctive moral vocabulary. These values and beliefs have multiple meanings that must be clarified and understood by prospective physicians who are expected to heal the person and the entire community (3). Lack of knowledge of values has generated communication barriers between physicians and patients which blur the

\section{Key words}

Values; medical education; values education; values journal; narrative writing. overall process of ethical decision-makingo Therefore, it is essential for physicians and medicat students to acquire a formal training in values, their role and their meanings. Yet the teaching of value and attitudes is largely ignored in most medicab school curricula. The result is that graduate medical students are ill-equipped and ill-prepared to deal with the complex ethical problems that arise if clinical settings $(4,5)$.

It is the assumption of this paper that fundamental principle of the values education programme is that a personal values system serves af a solid ground for a sound decision-making proces and as a basis for the professional conduct of the physician. Thus, teaching values must begin with thö students' awareness and understanding of their ow value systems, and with clarification of thei conception of quality of life.

A values education programme functions as $\bar{P}$ powerful vehicle for: (a) removing communicatio barriers and enhancing the professional-patien relationship; (b) helping physicians, families an $\widehat{\phi}$ patients to make sound, defensible choices and to pursue a good life; (c) allowing physicians to be mindful of social and cultural aspects of healt problems, and thus to develop a better understanding of the illness experience and, (d) encouraging collectivism and public dialogue that will sub sequently lead physicians and other health care. professionals towards common goals.

In the light of these purposes, this paper suggests that medical education should redirect resources to values education, specifically placing a greate $\varphi^{\mathrm{S}}$ emphasis on developing new strategies to improve the process of clarification of values. The use of the values journal method is suggested. This is based o a systematic record of students' personal value systems reflected in their stories and life experience and on their responses to case presentation Generating a personal value journal helps student? define who they are, what their social an 4 professional roles are, what their expectations are and where they are going. It promotes student $\$$ decision-making capacity, and equips them with the necessary skills to teach their future patients how ted generate their own value systems. In the following 
discussion I will introduce the concept of values and the existing techniques for eliciting values; and I will discuss in detail the proposed value journal method.

\section{What are values?}

The concept of values can be examined from several different perspectives. In general terms 'values' can refer to interests, pleasures, likes, desires, goals, needs and many other kinds of selective orientation (6). Kluckhohn (7) views values as:

'... a conception, explicit or implicit, distinctive of an individual or characteristic of a group, of the desirable which influences the selection from available modes, means, and ends of action' (8).

Accordingly, values have three dimensions: cognitive, affective and directive. The cognitive dimension refers to value as an internal code or mechanism that enables us to distinguish between good and bad, right and wrong (7), thus constituting the grounds for our decision-making process and the final course of action (9). Values function as a standard which assists individual decision-makers to formulate judgments and to select the most sound, acceptable and appropriate course of action (10). The affective dimension refers to values as an expression of human needs which create a specific mode of conduct or end-state of existence (6). Values project the state of desirability and human aspirations that are activated by human needs and predispositions. The directive dimension implies that values provide direction and guidance in resolving conflicts or dilemmas, and in coping with needs or claims for social and psychological defences of choices made (6). The amalgamation of cognition, affection and direction generates a comprehensive and inclusive notion of value.

Values can be classified into subsets or clusters of values: for example, basic values, moral values, social and political values, spiritual values and other more specific values.

Basic values include survival, caring, comfort, dignity, freedom, knowledge and self-respect. They are universal ends in themselves, and are rooted in human nature. Basic values represent the ultimate life-goals that people have. In order to promote these ultimate life-goals people need many intermediate or instrumental values that function as a means of attaining the fundamental or basic values. These instrumental values include moral, social and spiritual values (11). Moral values are one such subset and include carefulness, responsibility, courage, self-control, reliability, honesty and truthfulness. Spiritual values include awareness, breadth of outlook, integration and gratitude. Social and political values include peace, justice, cooperation, sharing, loyalty, solidarity and tolerance.

These diverse values are connected and ordered within a system that provides a frame for their ongoing interactive relationship and for weighing them against one another (11). The implication of the system approach to values and the relationship between basic values and other values can be illustrated by the following example. In order to pursue our well-being or happiness (ie, basic values) individuals have formed relational groups that are governed by social, moral and other values that allow them to cope effectively with environmental stress or hazards that may jeopardize their well-being. The formation of a group is a protective device to preserve its members' existence.

The stability and integrity of the group is highly dependent on people's social conduct, namely their adoption of moral values, rules, virtues or acceptable standards of conduct (ie, careful planning, responsibility, reliability and trustworthiness). These virtues are the tools that will ensure the mutually binding existence of human beings.

Basic values, like moral, social and spiritual values, are not absolute. They are changeable and carry a sense of fluidity. Their relative and interactive nature creates an ordered system in which values under particular occurrences are ranked in a list of priorities from the most to the least important. In other words, the individual value system is a solid base from which priorities or preferences can be established. Setting priorities is essential if we wish to maximize our wellbeing and to attain our basic life-goals. Preferences presuppose a hierarchy of values; they represent the level of importance one attaches to fundamental values under certain circumstances at a particular time and place (12). For example, if a patient values survival and comfort equally (two basic values) she may face a conflict between the two due to an acute illness that requires the intervention of a painful medical-technical procedure that might benefit her and prolong her life. The patient in this instance needs to sacrifice one value (comfort) in order to gain another basic value (survival). Thus, the specific expressed preferences of this particular patient will be survival and prolongation of life. Alternatively, another patient with a brain tumour who needs surgical intervention to prolong his life may prefer to forego the operation because he profoundly believes in dying with comfort and dignity under unobtrusive conditions.

Accordingly, an integrated and well defined value system, established and made explicit, will enable one to identify potential areas of conflict in the decision-making process and to determine short and long-range purposes, goals and priorities. Overall, a value system is a mirror-image of an individual's character and perception of well-being.

\section{What are the sources for eliciting values?}

A common technique for eliciting students' values is the case-study approach, which involves the presentation and analysis of a clinical case or a 
vignette. The analytic process can be approached through various theoretical frameworks that guide ethical inquiry. The students discuss the case using systematic guidelines, that is, they define the issue at stake, they identify the ethical and the clinical problem, they outline the sources of information which they need, they formulate a set of alternatives, they evaluate the alternatives; and at the end of the process they suggest a defensible resolution that is consistent with their value systems.

The presentation of a case probes the students' thought processes and reveals their hidden values, beliefs and concerns about the stated problem. The confrontation with an abstract task creates a context in which individuals are able to develop points of view, something they would not necessarily have time to do in real-life situations. The case triggers the students' internal code and references to past experience, and thus allows them to generate new thoughts or ideas about the present situation. It also affects the students' overt behaviour and their potential to make ethical decisions.

Another mode that promotes value inquiry and helps a student to build his or her own value framework is the student's personal lived experience or narrative. The student's narrative writing is a selfreported protocol that involves reflection upon past events, in which the student focuses on a selective portion of his or her experience in the clinical setting. The student attempts to identify and describe one critical event that has recently occurred. The student is encouraged to record (verbally or in writing) her interactive discourse with the involved patients. This includes: impressionistic accounts, observational cues, insights, negative and positive thoughts and feelings towards patients. The student is also encouraged to discuss and verbalize her feelings and concerns about the patient's demands and preferences.

The narrative writing process provides an opportunity to probe and reveal different patterns of moral behaviour reflected in the student's experiences. It also makes explicit external elements, such as organizational and contextual constraints that have an impact on her decisions. Furthermore, in following the detailed description of a particular event, students are encouraged to justify and provide explanations as to why they selected a specific course of action; thereby, to claim responsibility for their actions and their overall lived moral experience.

At this stage, faculty or clinical instructors have a critical role to play in helping students reflect on and evaluate their assumptions and preconceptions about a situation. Faculty can alert students to different constraints or presuppositions that hamper the way they understand the patient and his or her specific context. Faculty can also explore discrepancies between their own perceptions and interpretations of a situation and those of the students. The narrative enables the student and the faculty to generate a genuine dialogue in which both are taking control and responsibility over the content. and the process of the dialogue. The ongoing. dialogic relationship affects the faculty behaviour as well and as a consequence, they modify their owno values and professional behaviour, and thus learningo becomes a two-way process.

\section{The development of a values journal}

From the students' value statements as reflected in $\vec{\circ}$ their narratives, and the value statements that $-\overrightarrow{-}$ emerge in their responses to the clinical caseso presented, it is possible to draw comparisons and gradually to develop the values journal (13).

More specifically, in the first phase (the narrative) $)_{-}^{+}$ the student is asked to focus on a critical incident that had recently occurred either in his or her personal or professional life. For example, the student is asked to respond to the question: ' $\mathrm{Can}$ ? you recall a critical past event in which you were $\vec{c}$ involved and faced a serious dilemma?' Following the detailed description of the specific event, significant underlying values start to emerge. Theses values signify the overall attitudes of the student towards the specific problem.

In the second phase, the student is required to respond to a hypothetical case with which he or she is not personally involved: it is therefore expected that confrontation with this abstract objective task ${ }^{\circ}$ might generate different values, that would not necessarily appear in the description of their real-life 3 situation (phase I). The student is asked, for example, to define the ethical problem in the case, to suggest alternative modes of action to resolve the problem, and to justify the final chosen course of action.

After generating and comparing the two sets of. values it is possible to identify differences orô similarities in the students' value statements. This requires the assistance of a faculty member who음 examines, with the student, issues of consistency and $D$ inconsistency and the validity of each value in the list. The faculty member or the clinical teachern encourages the student to use a critical reflective process. Jointly they evaluate and determine which ${ }^{N}$ values are important to pursue, and what compromises must be made in a specific situation The evaluation process consists of answeringe questions such as how and why certain values have emerged, what their level of importance is, which of ${ }^{\circ}$ these values have personal significance and ${ }_{0}^{\circ}$ ultimately are worth pursuing and which will be sacrificed.

Faculty members must help students to be critical $\mathbb{Q}$ of their habitual expectations and belief systems (14) $\underset{\mathcal{Q}}{2}$ They should especially focus on communicativen learning that emphasizes inclusiveness, coherence 0 and integrity, helping students to reconcile conflicting value statements and subsequently to교 
generate direction and balance. In other words, this method fosters the reconstruction of an existing value system. The student is confronted with an opportunity to reflect upon her present state of knowledge, and subsequently to change, creating new knowledge and a new set of values.

The development of a well defined values journal is a preparatory stage for active participation in clinical conferences or group discussion, and for effective dialogue among the group's members. For example, an ethical problem can be presented in a clinical conference and then followed by a group discussion. Different opinions expressed by doctors, nurses and other health care providers may be discussed, and a consensual agreement subsequently reached among participants.

I believe that in this instance, participation is far more desirable if the student has already developed and consolidated his or her values journal prior to the group discussion. The student will be more confident about expressing her critically reflective assumptions and moral point of view and will be more attentive to others' voices. A well defined value system enables the student to participate effectively in a dialogic discourse that acknowledges her contributing efforts towards reaching a consensus, resulting in group integrity and shared social responsibility.

As the students' understanding of their own values becomes clearer, so their ability to appreciate the different moral points of view expressed by their patients will increase. Subsequently, as prospective well equipped physicians they will be able to use the values journal method with their patients, helping them to clarify their values and attitudes towards health care and assisting them to arrive at sound defensible decisions that are reflected and are consistent with the patients' values system.

Clarification of the patients' values is essential to the establishment of the physician-patient relationship and must precede any future negotiation process. If doctors will equip themselves with patients' values knowledge it will be easier to facilitate a dialogue which might result in compromises and alteration of the patients' behaviour. This is especially important nowadays, when on the one hand health care resources are limited but on the other hand consumers continue to proclaim a right to unrealistic treatments. Physicians will face tremendous strain with clients who, sooner or later, will have to realize that costly and nonbeneficial treatments are not attainable, and that compromises must be made. Unfortunately, at present, disputes between physicians and patients about treatment plans are often handled by transferring patients to the care of other physicians (15), thus avoiding professional responsibility and contributing to an episodic, distant and alienating mode of doctor-patient relationship.

I believe that lowering public demands and disciplining or aligning the public into a new existing reality, can be done through utilization of educational means as a proactive endeavour. An example of educational means can be the 'values journal method' that enables providers and patients to have a better understating of their own values, needs, expectations, role and place in society. Thus, the values journal can generate an effective and genuine dialogue that results in a desirable outcome.

Utilization of a 'values journal method' can assist physicians in generating an attitudinal shift among consumers, in that it can help them to change and modify patients' inappropriate demands and expectations from the health care system.

\section{Application of a values journal in daily practice}

The use of a values journal in daily practice can be illustrated through the formulation of advance directives and living wills. Advance directives should begin with the individual value system as a broad critical scale from which future directives can be given or decisions made (12). The individual values framework expressed in a carefully prepared journal is a solid base from which health care providers or others significantly involved (for example, proxies) can make inferences about the patient's desired choices. Advance directives which are properly generated will authentically reflect the individual conception of well-being that is composed of basic and other values. Therefore, if a health care provider wishes to help a patient to execute an advance health care directive, he or she needs to bear in mind that the patient's values journal must be completed as a prerequisite for determining future choices. The journal contains those values that are important and which have a significant bearing on a patient's life and which are therefore worth pursuing. It also includes those values which are less important and that can be sacrificed in particular circumstances. In addition, the journal will include evaluative comments and explanations of past events that are significant to the individual.

\section{Conclusion}

Values education should be in the forefront of medical education. Values are crucial to health care practice. They constitute the grounds for a sound and justifiable decision-making process. A personal values journal enables students and medical educators to develop a deeper understanding of who they are, what their ultimate goals are and where they are going. Without such an understanding it will be impossible to identify health care limits, reduce costs and balance the distribution of benefits and resources. If each of us will engage in research activity and a clarification process with respect to his or her own value system, we will be open to others' 
perspectives and an effective dialogue can take place. The clarification process singles out which similarities and differences exist in the group's value systems. A set of common, similar or shared values is the basis for reaching a group consensus. This leads to the development of a collective values framework that serves as the basis for formulating new health care policy guidelines that will be in keeping with basic needs and values.

\section{Acknowledgement}

This paper is partly based on my conference presentation, Making Choices in Health Care: An Ethics and Health Policy, in Baltimore, Maryland, USA. The conference was sponsored by the School of Nursing, University of Maryland at Baltimore and the Institute for Philosophy and Public Policy, University of Maryland at College Park.

Rivka Grundstein-Amado, BA, $M A, R N, P h D$, is a Bioethics Consultant, and Research Fellow at The Center for Medical Ethics, The Hebrew University, Hadassah Medical School, Ferusalem, Israel. Address for reprints: 8 Ha'haganna st, French Hill, ferusalem, Israel 97852.

\section{References}

(1) Pellegrino E D, Siegler M, Singer P A. Teaching clinical ethics. The journal of clinical ethics 1990; 1: 175-180.

(2) Miles S H, Weiss Lane L, Bickel J, Walker R M, Cassel C K. Medical ethics education: coming of age. Academic medicine 1989; 64: 705-714.

(3) Pellegrino E D. Educating the humanist physician. Fournal of the American Medical Association 1974; 227:
(4) Lipkin M. Community-oriented medical education today. In: Schmidt $H$ G, Lipkin $M$, de Vries $M$ W, Greep J M, eds. New directions for medica education: problem-based learning and community $\stackrel{\text { ? }}{+}$ oriented medical education. New York: Springer은 Verlag, 1989.

(5) Hensel W A, Rasco T L. Storytelling as a method for teaching values and attitudes. Academic medicine 1992; 67: 500-504.

(6) Rokeach M. The nature of human values. New York: The Free Press, 1973.

(7) Kluckhohn C. Values and value-orientations in the theory of action: an exploration in definition andw classification. In: Parson T, Shils E A, eds. Toward of general theory of action. Cambridge, MA: Harvaro University Press, 1951.

(8) See reference (7): 395.

(9) Kluckhohn F R, Strodtbeck F L. Variations in value orientations. Evanston, Illinois: Row, Person and Company, 1961.

(10) Grundstein-Amado R. An integrative model of clinical and ethical decision making. Theoretical medicine 1991 ; 12: 153-170.

(11) Beck C. Learning to live the good life: values in adulthood. Toronto: OISE Press, 1993.

(12) Grundstein-Amado R. Narrative inquiry: A methode for eliciting advance health care directives. Humane medicine 1992; 8: 31-39.

(13) Grundstein-Amado R. Ethical decision making processes in the health care system [dissertation] $\bar{\partial}$ Toronto: University of Toronto, 1990.

(14) Mezirow J. Toward transformative learning emancipatory education. In: Mezirow J et al, eds $\stackrel{\underline{\longrightarrow}}{\longrightarrow}$ Fostering critical reflection in adulthood: a guide tō․․ transformative and emancipatory learning. Oxford: The ${ }^{3}$ Jossey-Bass Publishers, 1990.

(15) Miles S H. Informed demands for 'non-beneficial medical treatment. The New England journal of medicine 1991; 325: 512-515.

\section{News and notes}

\section{Summer Seminar in Health Care Ethics}

A Summer Seminar in Health Care Ethics, sponsored by the Department of Medical History and Ethics, School of Medicine, University of Washington, will be held in Seattle, Washington, from July 31-August 4, this year. This annual Summer seminar is an intensive introduction to the concepts, methods, and cases of bioethics.

Albert Jonsen, Chair of the Department of Medical History and Ethics, will lead the seminar. The seminar is designed sufficiently to familiarise physicians, nurses, educators, chaplains, social workers, administrators, and other health care professionals with the field of bioethics, to enable them to make clinical-ethical decisions and to lead others in doing so.

For information on specific objectives, and to receive a seminar brochure with full details and registration form, contact: Marilyn J Barnard, Program Coordinator, Medical History and Ethics, SB-20, University of Washington, School of Medicine, Seattle, WA 98195. Phone: (206) 616-1864. Fax: (206) 685-7515. E-MAIL: mbarnard@u.washington.edu 